\title{
MORPHOMETRIC CHARACTERIZATION OF THE COLLUM CHIRURGICUM (SURGICAL NECK)
}

\author{
Nazli Gulriz Ceri ${ }^{1}$ \\ ${ }^{1}$ Department of Anatomy, Faculty of Medicine, Aydin Adnan Menderes University, Aydin, Turkey \\ Address for Correspondence: Nazli Gulriz Ceri. E-mail: drnazligulrizceri@gmail.com \\ Received: 07.01.2021; Accepted: 17.02.2021; Available Online Date: 26.02.2021 \\ (C) Copyright 2021 by Dokuz Eylül University, Institute of Health Sciences - Available online at https://dergipark.org.tr/en/pub/jbachs
}

Cite this article as: Ceri NG. Morphometric Characterization of the Collum Chirurgicum (Surgical Neck). J Basic Clin Health Sci 2021; 1: 35- 41.

\section{ABSTRACT}

Purpose: Surgical neck fractures have been a subject to vast numbers of researches, its structural dispositions depending on the variants of sex and directional morphometry requires further investigation. Therefore, we aimed to evaluate sex and side differences by using morphometric measurements of humerus and surgical neck.

Methods: In order to achieve the above-mentioned objective, measurements were performed on dry humerus specimens from 60 male and 60 female origins. The circumference of surgical neck (SNC) and humerus length $(\mathrm{HL})$ were measured in centimeter. After the completion of these measurements the area (SNA) of surgical neck was calculated and the data obtained was utilized to create two separate indexes.

Results: The circumference of surgical neck differed significantly between the sexes $(p=0.001)$, but not between the right-left sides $(p=0.054)$. Although there was a significant difference between male and female $H L$ on the right side $(p=0.001)$, there was no significant difference on the left side $(p=0.051)$. The highest mean value of the SNC in females $(7.13 \mathrm{~cm}$ ) was lower than the minimum value obtained in males $(7.20 \mathrm{~cm})$. The lowest mean value of the SNA in males $(4.92 \mathrm{~cm} 2)$ was higher than the maximum value obtained in females $(4.84 \mathrm{~cm} 2)$. There was a significant difference between sexes for both indexes $(p<0.05)$.

Conclusion: The morphometric data of this area may be utilized for forensic investigations, it may provide insight for the fracture treatments and solving clinical problems. We are opined that since the measurements of surgical neck varies in male and female samples, it may be an essentially important structure in determining sex of a given skeleton.

Keywords: Humerus, Collum Chirurgicum, Surgical Neck, Morphometry.

\section{INTRODUCTION}

Humerus, the thickest and longest bone of upper extremity, by forming the arm of the skeleton, also forms joints with scapula, radius and ulna. The narrowing area between major and minor tubercle and the body of the humerus is called the collum chirurgicum (surgical neck) (1). Proximal humeral fractures constitute approximately $5 \%$ of all fractures (2). Fractures of the proximal humerus account over $75 \%$ of all humeral fractures (3). In the last 5 years, the incidence of these fractures has increased by $15 \%$ (2). Surgical neck is a very frequently fractured area of the proximal humerus as the humerus begins to taper down at this point and is structurally weaker 
$(4,5)$. It is the third most common type of fracture in adults and is 2-3 times more would-be common in females than males. One reason is the decrease in bone density in females with advancing age (6-8). Axillary nerve and posterior humeral circumflex artery are adjacent to the medial part of the surgical neck and the surgical neck fractures may cause damage to these important structures (9). There are many clinical and morphometric studies on the humerus and its proximal part (10-14). However, studies investigating the morphometry of surgical neck, which is the most frequently fractured part, are almost nonexistent $(10,15)$. While, neck fractures have been a subject to vast numbers of researches $(16,17)$, its structural dispositions depending on the variants of sex and directional morphometry require further investigation. As the preceding studies usually endeavor to investigate humerus length comparisons between the male and female samples, they rarely pay attention to the surgical neck-based comparisons in measurements (12-14). Yet, surgical neck is the most fractured structure on the proximal humerus, and by this, we are opined that a special focus shall be spotted on the surgical neck's measurements for understanding its features. Although in the preceding studies, the measurements regarding surgical neck were not investigated in consideration of male and female differences (11-14), we observed a significant unlikeness of surgical neck measurements in male and female samples. Given the high clinical significance, but low number of investigations in this area, this study aimed to provide measurements on the surgical neck and evaluate the differences between the sexes and right-left sides

\section{METHODS}

A total of 120 dry adult humerus bones of Anatolian people belonging to 60 males (30 right, 30 left) and 60 females (30 right, 30 left) were included in the study. Only, humerus bones without any structural deformities were used. Bones were obtained from the bone archive of Aydin Adnan Menderes University. The bones in our archive were received from the municipality, having the records of the sex clearly defined.

At the beginning of the study, ten of the selected humerus were assessed independently by two anatomists. Ten days later, the same measurements were repeated and inter- and intra-observer reliability were assessed. All measurements were performed with tape measure of 0.1 millimeter $(\mathrm{mm})$ sensitivity. For the measurement of the humerus length $(\mathrm{HL})$ osteometric board tool was used (Figure 1A). The humerus length measured in centimeter $(\mathrm{cm})$ from the most superior point of the proximal part to the most inferior point of the distal part of the humerus. Circumference of the surgical neck (SNC) was measured at $1 \mathrm{~cm}$ below the lowest point on margin of articular surface of head of the humerus (Figure 1B). To find the surgical neck area (SNA), first, radius (r) was obtained with the formula $2 \pi r$ (circle circumference formula $=2 \pi r$ ) from the circumference measurements and then the formula $\pi \mathrm{r} 2$ (circle area formula $=\pi r 2)$ was used $(\pi: 3.14)$. We composed two different indexes by calculating the ratio of the humerus length to the surgical neck area (HL/ SNA) and the ratio of the diameter of the surgical neck to the humerus length. (SND/HL).

\section{Statistical Evaluations}

The measurements were transferred to SPSS for Windows release 11.0 for statistical analysis. Minimum, maximum, mean and standard deviation values of the data were determined in centimeter and compared with female-male, right-left using Independent Samples $\mathrm{t}$ test. Statistical significance was considered $p<0.05$.

\section{RESULTS}

In the pre-study realized in order to assess the accuracy of the measurements, it was seen that there was no inter- and intra-observer difference in regard to morphometrical parameters.

In Table 1, the value of the lowest mean of the circumference of the surgical neck (SNC) in the male humerus (left side) was $7.86 \pm 0.62 \mathrm{~cm}$ which was higher than the maximum value of the SNC obtained in the female humerus $(7.80 \mathrm{~cm})$. The value of the highest mean of the SNC in the female humerus (right side) was $7.13 \pm 0.43 \mathrm{~cm}$ which was lower than the minimum value of the SNC obtained in the male humerus $(7.20 \mathrm{~cm})$.

In Table 2, a significant difference was observed between the sexes in the SNC on both sides $(p=0.001)$. The SNC values on both sides were higher in males compared to females.

In Table 3, the highest value of the humerus length $(\mathrm{HL})$ was obtained in the male humerus $(35.20 \mathrm{~cm})$ 
Table 1. Measurements of the circumference of surgical neck

\begin{tabular}{|c|c|c|c|c|c|}
\hline SNC (cm) & Sexes & $\mathrm{n}$ & Min.-Max. (cm) & Mean $(\mathrm{cm})$ & SD \\
\hline Total Right-side & Male-Female & 60 & $6.2-9.0$ & 7.65 & .676 \\
\hline Total Left-side & Male-Female & 60 & $6.0-8.90$ & 7.41 & .747 \\
\hline Right-side & Male & 30 & $7.2-9.0$ & 8.18 & .403 \\
\hline Left-side & Male & 30 & $7.2-8.9$ & 7.86 & .620 \\
\hline Right-side & Female & 30 & $6.2-7.8$ & 7.13 & .439 \\
\hline Left-side & Female & 30 & $6.0-7.8$ & 6.96 & .580 \\
\hline \multicolumn{2}{|c|}{ Total Male } & 60 & $7.2-9.0$ & 8.02 & .544 \\
\hline \multicolumn{2}{|c|}{ Total Female } & 60 & $6.0-7.8$ & 7.04 & .517 \\
\hline
\end{tabular}

SD: Standard deviation; Min: Minimum; Max: Maximum; SNC: Circumference of the surgical neck

Table 2. T-test results from female-male comparison of the circumference of the surgical neck

\begin{tabular}{|c|c|c|c|c|c|}
\hline & Sexes & $n$ & $t$ & SD & $p$ \\
\hline & Male & 30 & & & \\
\hline Right-side & Female & 30 & 4.128 & 57.356 & 0.001 ^ \\
\hline Left-side & $\begin{array}{l}\text { Male } \\
\text { Female }\end{array}$ & $\begin{array}{l}30 \\
30\end{array}$ & 3.597 & 57.182 & $0.001^{*}$ \\
\hline
\end{tabular}

SD: Standard deviation; Min: Minimum; Max: Maximum; t: Student's t-test; ${ }^{*} \mathbf{p}<0.05$

Table 3. Measurements of the humerus length

\begin{tabular}{lccccc}
\hline \multicolumn{1}{c}{ HL $(\mathrm{cm})$} & Sexes & $\mathrm{n}$ & Min.-Max. $(\mathrm{cm})$ & Mean $(\mathrm{cm})$ \\
\hline Total Right-side & Male-Female & 60 & $25.60-35.20$ & 31.19 & 31.28 \\
Total Left-side & Male-Female & 60 & $27.90-34.80$ & 31.80 & 1.59 \\
Right-side & Male & 30 & $28.10-35.20$ & 32.08 & 1.47 \\
Left-side & Male & 30 & $29.80-34.80$ & 30.57 & 1.42 \\
Right-side & Female & 30 & $25.60-34.20$ & 30.47 & 1.85 \\
Left-side & Female & 30 & $27.90-32.60$ & 31.94 & 1.32 \\
& & 60 & $28.10-35.20$ & 30.52 & 1.44 \\
\hline
\end{tabular}

SD: Standard deviation; Min: Minimum; Max: maximum HL: The humerus length

and the lowest value was obtained in the female humerus $(25.60 \mathrm{~cm})$.

In Table 4, while there was no significant difference between male and female humerus length $(\mathrm{HL})$ on the left side, there was a significant difference between male and female $\mathrm{HL}$ on the right side. There was a significant difference between the sexes in the length of humerus when the right-left sides were not taken into account.

In Table 5, the value of the lowest mean of the surgical neck area (SNA) in the male humerus was $4.94 \mathrm{~cm} 2$, which was higher than the maximum value of the SNA obtained in the female humerus. The value of the highest mean of the SNA in the female humerus was $4.06 \mathrm{~cm} 2$, which was lower than the minimum value of the SNA obtained in the male humerus. A significant difference was observed between the sexes in the SNA on both sides. While there was no significant difference in the SNA between the sides in female, there was a significant difference in male.

In Table 6, a significant difference was observed between the sexes in the ratio of the humerus length measurements $(\mathrm{HL})$ to the surgical neck area (SNA) on both sides $(p=0.000)$. A significant difference was observed between the sexes in the diameter of the surgical neck (SND) to $\mathrm{HL}$ on both sides (right side $p=0.000$ and left side $p=0.004$ ). 
Table 4. T-test results of female-male humerus length

\begin{tabular}{|c|c|c|c|c|c|}
\hline & Sexes & $n$ & $t$ & SD & $p$ \\
\hline \multirow{2}{*}{ Right-side } & Male & 30 & \multirow{2}{*}{4.509} & \multirow{2}{*}{57.686} & \multirow{2}{*}{$0.001^{*}$} \\
\hline & Female & 30 & & & \\
\hline \multirow{2}{*}{ Left-side } & Male & 30 & \multirow{2}{*}{2.947} & \multirow{2}{*}{54.389} & \multirow{2}{*}{0.051} \\
\hline & Female & 30 & & & \\
\hline Both-side & Male & 60 & \multirow{2}{*}{5.088} & \multirow{2}{*}{116.79} & \multirow{2}{*}{$0.000^{*}$} \\
\hline Both-side & Female & 60 & & & \\
\hline
\end{tabular}

SD: Standard deviation; Min: Minimum; Max: Maximum; t: Student's t-test ${ }^{*} p<0.05$

Table 5. T-test results from female-male comparison of the area of the surgical neck

\begin{tabular}{|c|c|c|c|c|c|c|}
\hline & Sexes & Min-max & $\mathrm{N}$ & $t$ & SD & $p$ \\
\hline \multirow{2}{*}{ Right-side } & Male & $4.94-6.44$ & 30 & \multirow{2}{*}{9.845} & \multirow{2}{*}{57.852} & \multirow{2}{*}{$0.000^{*}$} \\
\hline & Female & $3.06-4.84$ & 30 & & & \\
\hline \multirow{2}{*}{ Left-side } & Male & $4.92-6.30$ & 30 & \multirow{2}{*}{5.740} & \multirow{2}{*}{55.810} & \multirow{2}{*}{$0.000^{*}$} \\
\hline & Female & $2.86-4.84$ & 30 & & & \\
\hline Right-side & \multirow{2}{*}{ Male } & $4.94-6.44$ & 30 & \multirow{2}{*}{2.308} & \multirow{2}{*}{50.195} & \multirow{2}{*}{$0.000^{*}$} \\
\hline Left-side & & $4.92-6.30$ & 30 & & & \\
\hline Right-side & \multirow{2}{*}{ Female } & $3.06-4.84$ & 30 & \multirow{2}{*}{1.192} & \multirow{2}{*}{54.311} & \multirow{2}{*}{0.006} \\
\hline Left-side & & $2.86-4.84$ & 30 & & & \\
\hline
\end{tabular}

SD: Standard deviation; Min: Minimum; Max: Maximum; t: Student's t-test; ${ }^{*} p<0.05$

Table 6. T-test results of female-male the ratio of the humerus length to the surgical neck area (HL/SNA) and the ratio of diameter of the surgical neck to humerus length (SND/HL)

\begin{tabular}{|c|c|c|c|c|c|c|}
\hline \multicolumn{7}{|c|}{ HL/SNA } \\
\hline & Sexes & $\mathrm{N}$ & Mean $\pm S D$ & $t$ & SD & $p$ \\
\hline \multirow{2}{*}{ Right-side } & Male & 30 & $6.00 \pm 0.61$ & \multirow{2}{*}{-7.494} & \multirow{2}{*}{47.594} & \multirow{2}{*}{0.000} \\
\hline & Female & 30 & $7.63 \pm 1.02$ & & & \\
\hline \multirow{2}{*}{ Left-side } & Male & 30 & $6.63 \pm 1.04$ & \multirow{2}{*}{-4.445} & \multirow{2}{*}{53.779} & \multirow{2}{*}{0.000} \\
\hline & Female & 30 & $8.05 \pm 1.39$ & & & \\
\hline \multicolumn{7}{|c|}{ SND/HL } \\
\hline & Sexes & $\mathrm{N}$ & Mean $\pm S D$ & $\mathrm{t}$ & SD & \\
\hline \multirow{2}{*}{ Right-side } & Male & 30 & $0.08 \pm 0.004$ & \multirow{2}{*}{5.498} & \multirow{2}{*}{54.358} & \multirow{2}{*}{0.000} \\
\hline & Female & 30 & $0.07 \pm 0.006$ & & & \\
\hline \multirow{2}{*}{ Left-side } & Male & 30 & $0.08 \pm 0.007$ & \multirow{2}{*}{3.011} & \multirow{2}{*}{57.804} & \multirow{2}{*}{0.004} \\
\hline & Female & 30 & $0.07 \pm 0.006$ & & & \\
\hline
\end{tabular}

SD: Standard deviation t: Student's t-test; ${ }^{*} \mathrm{p}<0.05 \mathrm{HL}$ : The humerus length; SNA: The surgical neck area; SND: Diameter of the surgical neck
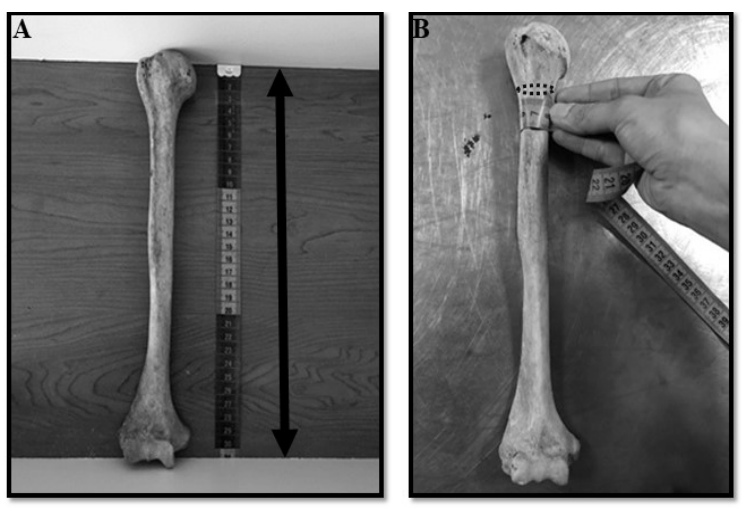

Figure 1: The measurement of the humerus. A) The measurement of the humerus length; B) The measurement of the surgical neck

\section{DISCUSSION}

Factors such as bone quality, age and sex are effective in the treatment of fracture $(18,19)$. For example, intramedullary nailing is a surgical procedure that is frequently used in the surgical neck fractures due to lower complication rate $(20,21)$ However, it is not an appropriate method of treatment for fractures with poor bone quality (22). There are studies emphasizing that in surgical treatment of proximal humerus fractures, decreasing of the bone density will negatively affect surgical fixation $(23,24)$ and therefore it is important to evaluate bone quality $(25,26)$. In our study, morphometric parameters of female surgical neck were significantly lower than 
male's ( $p=0.001$ ). For this reason, in the treatment of fractures of this region, besides bone quality anatomical evaluation depends on gender is also clinically important.

Various bones are frequently used for sex and race determination in anatomy, anthropology and forensic studies. The humerus is a preferred bone related to sex and race determination (15, 27-29). In the studies performed in this area, it was concluded that the maximum diameter of the humeral head, the epicondylar width and the maximum length of the humerus are the most useful and the best discriminative measures in the determination of sex (10-14). In our study, there was a significant difference between the humerus length measurements from males and females $(p=0.001)$. Although scarce volume of investigations is being carried out in respect of the surgical neck's morphometric measurements, the studies mainly continue to focus on frequent humerus measurements $(13,14)$. But in our study, a significant difference was observed between the female and male surgical neck measurements (SNC, SNA and indexes HL/SNA and SND/HL) on the both sides. We think that using morphometric properties of the surgical neck can be an important measure in sex determination.

A study by Ahmed et al (15), a total of 176 humerus bones (46 female, 130 male), evaluated in India. The circumference of the surgical neck was found to be $7.99 \pm 0.70 \mathrm{~cm}$ in male, $9.08 \pm 0.63 \mathrm{~cm}$ in female. The results of the circumference of the surgical neck in our study were lower than the circumference of the surgical neck reported earlier. We thought that this situation could be well explained by race-related differences in anatomy.

Barnes et al (10) found the mean humeral length was $39.67 \pm 2.61 \mathrm{~cm}$ in right side of the female, $40.00 \pm 2.23$ $\mathrm{cm}$ in left side; and $45.38 \pm 2.95 \mathrm{~cm}$ in right side of the male, $44.78 \pm 2.48 \mathrm{~cm}$ in left side. In our study, the maximum length of the humerus on the right side was $31.8 \pm 1.47 \mathrm{~cm}$ for males and $30.57 \pm 1.85 \mathrm{~cm}$ for females, on the left side was $32.08 \pm 1.42 \mathrm{~cm}$ for males and $30.47 \pm 1.32 \mathrm{~cm}$ for females. A study by Ogedengbe et al. (30) was carried out on a sample from a KwaZulu-Natal population and found that the mean the length of the humerus was $32.08 \pm 1.79 \mathrm{~cm}$ on the males, $29.46 \pm 1.55 \mathrm{~cm}$ on the females, irrespective of right and left side. The other study (31) is composed of 104 white and 88 black population in South Africans. The mean length of the humerus in white female population was $30.9-16.7 \mathrm{~cm}$, in white male population was $33.5 \pm 17.9 \mathrm{~cm}$; in black female population was $29.47 \pm 15.0 \mathrm{~cm}$, in black male population was $32.8 \pm 14.8 \mathrm{~cm}$. In a study conducted in India (32), the mean of the humerus length was $31.07 \pm 1.41 \mathrm{~cm}$ on the males, $7.81 \pm 1.54 \mathrm{~cm}$ on the females. In these studies, we mentioned $(10,30-32)$ and our study, humerus length showed a significant difference between the sexes. Humerus length mean values of male were higher than female. However, in the study of Dare et al. (33) the humerus length values of Kenyan female were quite high compared to male. Different results in these studies were thought to be related to sex determination.

\section{CONCLUSION}

The morphometric data of the surgical neck is important in sex determination. Thus, within this scope, such feature may have an important supplementary value in respect of forensic investigations. Yet, even though there exist abundance of clinical and morphometric studies on the humerus and its proximal part, researches on surgical neck is close to none. Also, considering the lack of consensus for treating surgical neck fractures, we are opined that this area requires further and elaborate investigation for comprising its fundamental treatment methods and procedures. Hence, the knowledge and the comprehension towards it anatomic features shall be evaluated in time. In this respect we think that our work will provide a contribution towards clinical approach.

Acknowledgements: We would like to thank to Gizem Sakalli, $\mathrm{PhD}$ student, for her contribution to data collection.

Conflicts of Interest: No potential conflict of interest relevant to this article was reported.

Peer-review: Externally peer-reviewed.

\section{REFERENCES}

1. Standring S. Gray's anatomy. The Anatomical Basis of Clinical Practice. 40st ed. Elsevier; 2015.p.804-808.

2. Jamal L, Cherrad T, Bousbaa H, Wahidi M, Amhajji $\mathrm{L}$, Rachid K. Centro-medullary nailing in the complex fractures of the upper end of the humerus: Preliminary results in 6 . The Pan African Medical Journal 2016; 25: 54. 
3. Schumaier A, Grawe B. Proximal humerus fractures: evaluation and management in the elderly patient. Geriatric Orthopaedic Surgery \& Rehabilitation 2018; 9: 1-11.

4. Hansen JT. Netter's clinical anatomy. Elsevier Health Sciences; 2014.p.293-306.

5. Demirtaş M, Aydin M. Humerus üst uç kırıklarında kilitli plak ile tespit ve minimal invaziv cerrahi uygulamalar. Totbid Dergisi 2012; 11(1): 20-27.

6. Lind T, Krøner K, Jensen J. The epidemiology of fractures of the proximal humerus. Arch Orthop Trauma Surg 1989; 108(5): 285-287.

7. Aydin Kabakci AD, Buyukmumcu M, Yilmaz MT, Cicekcibasi AE, Akın D, Cihan E. An Osteometric Study on Humerus. International Journal of Morphology 2017; 35(1).

8. Roux A, Decroocq L, El Batti S, et al. Epidemiology of proximal humerus fractures managed in a trauma center. Orthop Traumatol Surg Res 2012; 98(6): 715-719.

9. Kulkarni NV. Clinical Anatomy (A Problem-Solving Approach). 3st ed. Jaypee Brothers Medical Publishers; 2011.p.75-76.

10. Barnes J, Wescott DJ. Sex determination of mississippian skeletal remains from humeral measurements. The Missouri Archaeologist, Journal of the Missouri Archaeological Society 2007; 68: 133-137.

11. Kranioti EF, Michalodimitrakis M. Sexual dimorphism of the humerus in contemporary cretans-a population-specific study and a review of the literature. J Forensic Sci 2009; 54(5): 9961000.

12. Al Shehri F, Soliman KE. Determination of sex from radiographic measurements of the humerus by discriminant function analysis in Saudi population, Qassim region, KSA. Forensic Sci Int 2015; 253: 138.

13. Khan MA, Gul H, Nizami SM. Determination of gender from various measurements of the humerus. Cureus 2020; 12(1): e6598.

14. Christiano AV, Pean CA, Leucht $P$, Konda SR, Egol KA. Scoring of radiographic cortical healing with the radiographic humerus union measurement predicts union in humeral shaft fractures. Eur J Orthop Surg Traumatol 2020; 30(5): 835-838.

15. Ahmed SS, Siddiqui FB, Bayer SB. Sex differentiation of humerus: an osteometric study. Journal of Clinical \& Diagnostic Research 2018; 12(12): $1-5$
16. Huang $\mathrm{H}$. Treatment of the surgical neck fracture of the humerus with a novel external fixator in the elderly with osteoporosis: biomechanical analysis. BMC Musculoskelet Disord 2019; 20(1): 218

17. Cai $P$, Yang $Y, X u Z$, Wang $Z$, Zhou $X$, Yang T. Anatomic locking plates for complex proximal humeral fractures: anatomic neck fractures versus surgical neck fractures. Journal of shoulder and elbow surgery 2019; 28(3): 476482.

18. Harrison AK, Gruson KI, Zmistowski B, et al. Intermediate outcomes following percutaneous fixation of proximal humeral fractures. JBJS 2012; 94(13): 1223-1228.

19. Fenichel I, Oran A, Burstein G, Perry, M. Percutaneous pinning using threaded pins as a treatment option for unstable two-and three-part fractures of the proximal humerus: a retrospective study. Int Orthop 2006; 30(3): 153157.

20. Horn J, Gueorguiev B, Brianza S, Steen H, Schwieger K. Biomechanical evaluation of twopart surgical neck fractures of the humerus fixed by an angular stable locked intramedullary nail. $\mathrm{J}$ Orthop Trauma 2011; 25(7): 406-413.

21. Maier $D$, Jäger $M$, Strohm $P C$, Südkamp NP. Treatment of proximal humeral fractures-a review of current concepts enlightened by basic principles. Acta Chir Orthop Traumatol Cech 2012; 79(4): 307-316.

22. Kocadal O, Aktekin CN. Treatment of proximal humeral fractures: a current concept. Turkiye Klinikleri Journal of Orthopaedics and Traumatology 2015; 8(4): 25-32.

23. Kralinger F, Blauth M, Goldhahn J, et al. The influence of local bone density on the outcome of one hundred and fifty proximal humeral fractures treated with a locking plate. JBJS 2014; 96: 1026-1032.

24. Krappinger D, Bizzotto N, Riedmann S, Kammerlander C, Hengg C, Kralinger FS. Predicting failure after surgical fixation of proximal humerus fractures. Injury 2011; 42(11): 1283-1288.

25. Hertel RW. Fractures of the proximal humerus in osteoporotic bone. Osteoporos Int 2005; 16: 6572.

26. Olerud $P$, Ahrengart L, So"derqvist A, Saving J, Tidermark J. Quality of life and functional outcome after a 2-part proximal humeral fracture: 
A prospective cohort study on 50 patients treated with a locking plate. J Shoulder Elbow Surg 2010; 19: 814-822.

27. Desai S, Shaik HS. A morphometric study of humerus segments. Journal of Pharmaceutical Sciences and Research 2012; 4(10): 1943-1945.

28. Holman DJ, Bennett KA. Determination of sex from arm bone measurements. Am J Phys Anthropol 1991; 84(4): 421-426.

29. Somesh MS, Prabhu LV, Shilpa K, et al. Morphometric study of the humerus segments in Indian population. Int J Morphol 2011; 29(4): 1174-1180.

30. Ogedengbe OO, Ajayi SA, Komolafe OA, Zaw AK, Naidu ECS, Okpara Azu O. Sex determination using humeral dimensions in a sample from KwaZulu-Natal: an osteometric study. Anat Cell Biol 2017; 50(3): 180-186.

31. Reddy BB, Doshi M. Sex determination from adult human humerus by discriminant function analysis. International Journal of Research in Medical Sciences 2017; 5(9): 3891-3897.

32. Steyn M, İşcan MY. Osteometric variation in the humerus: sexual dimorphism in South Africans. Forensic Sci Int 1999; 106(2): 77-85.

33. Dare SS, Masilili G, Mugagga K, Ekanem PE. Evaluation of bilateral asymmetry in the humerus of human skeletal specimen. BioMed research International 2019; 2019: 1-11. 